\title{
La Ley 29497, Nueva Ley Procesal del Trabajo: a propósito de la oralidad y la celeridad
}

\section{Germán Ramírez-Gastón}

Bienvenidos al Encuentro académico sobre la Ley 29497, Nueva Ley Procesal del Trabajo.

Esta ley trae una serie de novedades, entre ellas la oralidad y la celeridad en el proceso laboral, así como la utilización de herramientas de tecnología en el desarrollo del proceso.

Norma de vital importancia, se ha venido aplicando como piloto en algunos departamentos y provincias alejadas de la capital, aunque su implementación en la ciudad de Lima se hará a partir del 3 de noviembre del 2012. Un gran reto es la capacitación de los jueces, de los litigantes y de los abogados en el empleo de este nuevo proceso, con el fin de alcanzar una correcta administración de justicia.

Para tratar los novedosos temas que nos plantea la aplicación de la nueva norma procesal laboral, contamos esta noche con la presencia de distinguidos abogados y panelistas, especializados en el área del derecho del trabajo, quienes nos ilustrarán sobre las bondades y problemas de su aplicación.

En primer lugar, quiero presentar a Michael Vidal Salazar, abogado graduado en la Pontifica Universidad Católica del Perú y docente en esa misma casa de estudios. Es también miembro de la Sociedad Peruana 
del Trabajo y la Seguridad Social y gerente de Human Capital en Ernst \& Young, prestigiosa compañía de auditores.

En segundo lugar, contamos con Eduardo Mercado Villarán, abogado graduado igualmente en la Pontificia Universidad Católica del Perú, asociado del área laboral del Estudio Miranda \& Amado Abogados, especializado en la elaboración de estrategias procesales laborales y en la defensa y litigación oral en procesos laborales y/o procedimientos administrativos laborales. Es autor de numerosos artículos en su especialidad.

En tercer lugar, también hablará sobre el tema Carlos Alberto Quispe Montesinos, abogado por la Pontificia Universidad Católica del Perú, juez especializado de trabajo de la Corte Superior de Lima y docente de la Maestría de Derecho del Trabajo de la Universidad de San Martín de Porres, además de miembro de la Sociedad Peruana de Derecho del Trabajo y la Seguridad Social.

Y, en cuarto lugar, contamos con la presencia de Cinthya Briceño Jiménez, abogada graduada en la Universidad de Lima y miembro del Estudio Rodrigo, Elías y Medrano Abogados, en donde se encarga de la dirección de los procesos judiciales laborales de prestigiosas empresas de los sectores público y privado.

Sin más preámbulos, y con la finalidad de que todos los panelistas cuenten con tiempo suficiente, empezaremos de inmediato con la primera exposición, la que estará a cargo de Michael Vidal Salazar.

\section{Michael Vidal Salazar}

Muchas gracias, doctor Ramírez Gastón, y gracias a la revista por la invitación. Voy a hacer una exposición general recogiendo los distintos puntos que han sido consignados en la agenda, para luego, a partir de la exposición de las personas que hoy me acompañan, aterrizar en determinados temas puntuales.

El primer tema planteado, y que seguramente es la gran novedad en la nueva ley, es el referido a la oralidad, que no es otra cosa que la prevalencia de la actuación oral frente a la actuación escrita. Así pues, la oralidad no supone una actuación totalmente oral, sino que admite también cierta actuación escrita. A partir de la prevalencia de lo oral sobre lo escrito, nos encontramos con lo que en la doctrina se conoce como un proceso por audiencias, donde dicha parte (la audiencia) se constituye en la instancia más importante del proceso. 
Hoy día, la Ley 26636 también recoge rasgos de oralidad; sin embargo, sigue primando lo escrito sobre lo oral, lo que ha derivado en que, por ejemplo, las audiencias en los procesos tramitados con la Ley 26636 tengan un papel secundario.

En todo caso, la oralidad recogida en el esquema del nuevo proceso laboral constituye, y ello es muy relevante, un reconocimiento mayor de la tutela jurisdiccional efectiva. Desde nuestro punto de vista, todo cambio procesal debe apuntar a ese mayor reconocimiento, que se manifiesta en la regulación de un proceso más célere y se constituye en un medio fundamental para conseguir ese objetivo, el de la aplicación de un sistema oral, donde además resulta de suma importancia la valoración de principios como el de concentración y el de inmediación.

A partir de lo señalado, la entrada en vigencia de la Nueva Ley Procesal del Trabajo resulta un fenómeno bastante positivo. Las estadísticas nos dicen que los procesos tramitados con la nueva ley tienen una duración de alrededor de un año y medio, duración que puede llegar hasta los dos años. Comparado con los cinco o seis años que podría alcanzar un proceso tramitado con la Ley 26636, el avance es importante.

En todo caso, las demoras que pueden haber ocurrido en la tramitación de los procesos con la nueva ley, no han derivado de la estructura del proceso mismo, sino de factores que tienen que ver con recursos materiales y recursos humanos, es decir, con la falta de elementos logísticos y con material humano insuficiente para atender la carga procesal generada. A ello se puede sumar un incipiente manejo de los operadores dentro del proceso, tanto de quien tiene que juzgar como de quienes recurren al proceso para la solución de un conflicto (demandante y demandado). En definitiva, hay un derecho de piso que deberán pagar el nuevo proceso laboral y sus actores; sin embargo, ello no desmerece lo positivo de la reforma.

A los puntos señalados se suma la necesidad de entender qué significa la oralidad. Han surgido problemas y discusiones que llevan a reevaluar qué supone en un sentido práctico. Por ejemplo, un tema planteado es el de la posibilidad de modificar la demanda. Hay quienes sostienen que la oralidad le otorga al demandante la ocasión de actualizar o modificar su demanda en una etapa posterior a la de postulación. Nosotros creemos que la oralidad debe ser entendida en relación con los principios de concentración, inmediación, celeridad y publicidad; de lo contrario, es probable que no se alcancen los objetivos para los que fue 
pensada. En esa línea, aceptar que la demanda pueda ser modificada en cualquier momento puede afectar esa idea, en especial porque podría suponer una afectación directa de los principios de celeridad e inmediación: es probable que otorgar tal posibilidad al demandante genere retrasos en el proceso y, con ello, la eventualidad de que quien sentencie el proceso no sea el juez que lo tramitó desde su inicio. Y es que, en virtud del derecho de defensa, el demandado también debería tener la facultad de modificar su contestación y aportar, de ser necesario, nuevas pruebas, lo que podría significar un regreso a la etapa postulatoria del proceso.

Otro asunto tratado hace poco está relacionado con el concepto de "teoría del caso". Al respecto, una resolución emitida recientemente por la Corte Suprema declaró infundado un recurso de casación por considerar que estaba basado en un cambio en la teoría del caso del recurrente. Quien lo interpuso sustentaba su posición en nueva jurisprudencia emitida sobre la materia en discusión, lo que fue considerado por la Corte Suprema como un cambio en la teoría del caso. Esta situación ha generado una importante discusión sobre lo que debería entenderse por "teoría del caso", elemento sustancial en un proceso oral.

Todo lo anterior evidencia que aún existen cosas que afinar con relación a la oralidad, lo que no debe perjudicar, sin embargo, la visión positiva del cambio.

Por otro lado, en cuanto al aspecto probatorio, considerado en la agenda, también tengo una posición positiva.

$\mathrm{Al}$ respecto, el tema que más ha estado en vitrina es el de la presunción de laboralidad, es decir, la presunción de la existencia de una relación laboral a partir de la sola acreditación de una prestación personal de servicios, siendo de cargo del demandado el probar lo contrario. Es verdad que esta medida le endurece la carga probatoria al demandado, el posible empleador, aunque es cierto también que ello va de la mano con la facilitación probatoria que debe recoger un proceso laboral como proceso en el cual el trabajador, el demandante, no tiene acceso a los medios probatorios suficientes porque estos están, comúnmente, en poder del posible empleador. Ello, seguramente, va a significar un cambio en relación con las prácticas de las empresas en el momento de contratar servicios. Vuelve necesaria, además, una mayor capacitación, una mayor prevención, una mayor organización de los archivos (para tener los documentos y poderse defender en un eventual proceso), $\mathrm{y}$, 
sobre todo, un cambio de mentalidad en las políticas de contratación. Si hoy día algo se le puede sugerir a una empresa es que no tome servicios de una persona natural bajo un contrato civil, sino que, en la medida de lo posible, lo haga mediante un contrato laboral, pues es probable que un contrato de locación de servicios con una persona natural le provoque una contingencia. Otra materia relacionada con el aspecto probatorio es la referida a los hechos lesivos de derechos fundamentales. La norma establece que, ante un posible hecho de esa naturaleza, quien es acusado de haberlo perpetrado tendrá que demostrar los fundamentos razonables, legales, justos de tal hecho; en otras palabras, tendrá que probar que el hecho se materializó dentro de la ley y que hubo una razón para ello. Esto se vincula, por ejemplo, con el despido nulo, en donde el empleador no sólo tendrá que alegar que su decisión no estuvo motivada en un supuesto de nulidad, sino que además deberá probar cuál fue la verdadera causa por la que decidió separar al trabajador. Con ello se obtiene también una mayor tutela jurisdiccional a quien se considera víctima de un despido nulo.

En relación con las novedades de la ley, rescataría, además de la oralidad y la facilitación probatoria, la ampliación del ámbito de la justicia laboral. En esa línea, se ha acercado la justicia a las personas, situación que, por ejemplo, se puede observar en materia de competencia. Hoy el juez de paz letrado tiene un mayor ámbito de acción, lo que quizá no es muy trascendente en Lima, pero sí en interior del país, donde muchas veces aquel juez es el más cercano al demandante. Asimismo, se ha ampliado el ámbito a grupos de personas que antes no podían acceder a la justicia laboral, como los vinculados a las modalidades formativas, entre ellas los practicantes, que ahora pueden asistir a un juez laboral para reclamar el incumplimiento de obligaciones de quien los contrata, derivadas de su situación de practicantes, y no solo cuando consideran desnaturalizada la contratación formativa.

Otro tema novedoso es la mayor efectividad recogida en la nueva ley, dentro de un esquema de mayor tutela jurisdiccional efectiva. Dos ejemplos clarísimos son la regulación de las medidas cautelares y del recurso de casación. En relación con lo primero, se ha considerado la posibilidad de solicitar cualquier medida cautelar, incluso una previa al proceso, conocida como medida cautelar fuera del proceso Con relación al recurso de casación, hay novedades en sus efectos: la nueva ley establece que la interposición del recurso no suspende los efectos de la 
sentencia recurrida, todo lo contrario a lo previsto por la Ley 26636. Ello es trascendente, pues, cuando comentábamos que un proceso tramitado con esta última norma podía durar cinco o seis años, dos o tres años de ese tiempo podían irse en la tramitación ante la Corte Suprema, situación que ahora ya no debería causar un perjuicio al demandante en tanto el demandado se verá obligado a cumplir con lo establecido por la sentencia de segunda instancia, aunque exista un recurso de casación en trámite, salvo que presente una carta fianza o depósito judicial por el monto ordenado y sólo en supuestos de reclamos económicos. En caso de reclamos no económicos, como uno de reposición, ni siquiera existe esa posibilidad.

En cuanto a los defectos, es seguro que hay muchas cosas que mejorar, pero lo más importante es tratar de dar un mayor impulso a cuestiones que son complementarias al texto legal, como la capacitación de los órganos jurisdiccionales o abogados que van a litigar en estos procesos.

Por último, con respecto a las recomendaciones, debo remarcar la necesidad de cambiar la visión del proceso laboral y dejar de considerarlo como un mecanismo dilatorio del cumplimiento de obligaciones. El demandado debe entender que si su posición no está sustentada no solo en derecho, sino en un material probatorio adecuado, ni el mejor abogado del país podrá conseguirle un resultado favorable. Ello puede llevarle, además, a evaluar si en determinados casos dejar que un conflicto llegue a una instancia judicial es una buena alternativa.

\section{Germán Ramírez-Gastón}

Agradecemos la brillante participación de Michael Vidal, pues en el poco tiempo que le fue asignado, nos ha dado una visión completa y transversal de la ley.

He podido resumir algunos puntos importantes de su exposición, que valen la pena resaltar. En primer lugar, ha dicho que la oralidad va de la mano con la celeridad e implica un mayor reconocimiento en la tutela jurisdiccional a favor del trabajador, y ha comentando sobre diferentes problemas que suscita la aplicación de la nueva ley.

Ha planteado si se puede modificar la demanda después de la contestación, tema no previsto, pero que suscita debate. También ha hecho énfasis en el aspecto probatorio de la nueva ley con respecto a la presun- 
ción de laboralidad, donde basta la prestación personal para que se presuma la existencia de subordinación, con lo que dicho elemento adquiere mayor relevancia frente a la primacía de la realidad, que se encuentra circunscrita a que el trabajador pruebe, además de la prestación personal, la existencia de la subordinación.

Cabe destacar también la referencia a las novedades de la nueva ley procesal al acercar la justicia a las personas y el nuevo alcance de la norma, que incorpora dentro de ella a quienes prestan sus actividades bajo las modalidades de formación laboral y juvenil.

Otro punto destacable lo constituyen las medidas cautelares, que incluso pueden ser presentadas antes de iniciado el proceso laboral, así como los efectos del recurso de casación, el que no suspende lo resuelto en segunda instancia, siendo necesario proceder a la consignación o a la presentación de una carta fianza cuando el fallo contenga pago de dinero.

Estoy seguro de que estos comentarios serán a su vez comentados por los siguientes panelistas y con mayor énfasis.

\section{Eduardo Mercado Villarán}

Muchas gracias a la revista por la invitación. Michael Vidal ha hecho una exposición bastante clara sobre lo que significa la aplicación de la Nueva Ley Procesal del Trabajo y ha dejado una serie de temas para el debate. Sin embargo, la idea de este conversatorio es también analizar cómo la nueva ley se ha implementado en distintas sedes judiciales, así como analizar otros aspectos procesales suyos y saber en qué medida coadyuvan en la aplicación del derecho sustantivo laboral. Debemos tener en cuenta que lo que debe hacer una norma procesal es estar en posibilidad de proporcionar tutela jurisdiccional efectiva, a fin de que una norma sustantiva que me otorga determinado derecho pueda ser cumplida de forma eficaz.

¿Qué es lo que sucedía con la Ley 26636? En primer lugar, los procesos solían durar entre cuatro y cinco años y constaban de tres etapas: la primera instancia (etapa inicial del proceso); la segunda instancia (revisión), ante una sala especializada (Lima); y, por último, la posibilidad de ir a casación, estadio procesal en el que los juicios se dilataban entre uno y dos años (mientras, había un pronunciamiento sólo sobre la procedencia o improcedencia de un determinado recurso), 
lo que demostraba que estos procesos no cumplían con una de las principales prerrogativas que tiene o debe tener una norma procesal: proporcionar una real y efectiva tutela jurisdiccional. Si obtenemos una sentencia que nos da la razón, pero se emite después de cuatro o cinco años, quizá ya no vaya a ser efectiva ni pueda ser cumplida en los hechos. Esto nos lleva a pensar que el proceso laboral (Ley 26636) no se estaba aplicando de acuerdo con la necesidad de los justiciables, en este caso, los trabajadores.

Ante una justicia lente y poco eficaz, el Estado intenta brindar una solución promulgando la Nueva Ley Procesal del Trabajo, que recoge una serie de experiencias de otros países de Latinoamérica, como Chile, Colombia y Venezuela, con algunas diferencias, por supuesto, todo ello con la intención de contar con un proceso laboral eficaz, con procesos mucho más céleres, como bien lo ha indicado Michael Vidal. Esta celeridad va de la mano con la oralidad, herramienta que, sumada a la inmediación y la concentración, ha permitido reducir en forma considerable el tiempo que dura un proceso judicial laboral.

Cabe señalar que el primer proceso que se resolvió en sede casatoria, con la Nueva Ley Procesal del Trabajo, duró en promedio un año y seis meses (sumadas todas las etapas), frente a los cinco años que tomaba un proceso ordinario laboral con la Ley 26636. Es evidente que la nueva ley está permitiendo una mayor tutela jurisdiccional efectiva que la proporcionada por la 26636, lo que ocurre por una serie de razones, entre ellas la revaloración de los principios.

Antes, principios como la inmediación, la concentración, la celeridad o la oralidad - también presentes en la antigua ley- se apreciaban ideales, etéreos; hoy se aplican y se advierte la necesidad de su presencia para dinamizar el proceso. Por ejemplo, la oralidad, una de las herramientas principales según Michael Vidal, permite no solo que los procesos sean céleres, sino que los demás principios estén presentes. En efecto, la inmediación y la concentración dejaron de ser solo principios, para darle sustancia al proceso. En estos procesos existen dos modalidades: el proceso abreviado laboral, concentrado en una sola audiencia y en un solo acto, y el proceso ordinario laboral, dividido en dos audiencias: una de conciliación, donde las partes se apersonan ante el juzgado, verifican si hay opción de conciliar - para eso, cada parte analiza su posición y los jueces actúan participativamente, teniendo como regla general el apagado del audio y el video de la audiencia, a fin de que las 
partes puedan ponerse de acuerdo- $-\mathrm{y}$, si no hay acuerdo, el demandado contesta la demanda y se señala una segunda audiencia: de juzgamiento, donde en un solo acto se confrontan las posiciones (alegatos de inicio) y, luego de verse qué hechos requieren de prueba y qué hechos no, se realiza la actividad probatoria y se concluye con los alegatos de cada parte - que suponen los hechos narrados en el proceso, unidos a la actividad probatoria y la consecuencia jurídica que se generaría como efecto de esto-, luego de lo cual el juez debe emitir sentencia.

Entonces, tenemos un proceso, el ordinario laboral, en el que en dos actos ya se está emitiendo sentencia, y uno abreviado, de un solo acto. Cabe señalar que, a diferencia del proceso ordinario, cuando me citan en el proceso abreviado para ir a la audiencia de conciliación, si yo no concilio, el juez corre traslado de contestación de la demanda - que ha sido presentada con anterioridad - y, como consecuencia de ello, la parte demandante revisa el documento y se inicia la segunda parte de la audiencia, que seria el símil de la audiencia de juzgamiento, todo en un solo acto. Es aquí donde podemos observar cómo la concentración dejó de ser un principio etéreo, para ser realmente parte del proceso, y lo mismo sucede con la inmediatez, pues si bien esta es el medio por el cual el juez está de manera más cercana a las partes, se revaloriza o se caracteriza porque en ese momento (audiencia) el juez puede aprovechar la presencia de aquellas para hacer las preguntas que considere pertinentes sobre algún hecho o algún aspecto que considere que no queda claro; el juez tiene toda la facultad de preguntar a las partes cuanto crea necesario.

Así pues, considero que hay una revalorización de los principios, que en la antigua ley eran etéreos, muy principistas, por decirlo de alguna forma, a diferencia de lo que sucede con la nueva ley, donde están presentes y son necesarios en el proceso - porque, si no, como mencionamos, no se podría conseguir lo que se está buscando: una tutela jurisdiccional efectiva - y esto como consecuencia ha generado una reconfiguración del proceso laboral.

Como he dicho, el antiguo proceso tenía una serie de pautas, que se iban perdiendo en el camino, con una serie de documentos (pruebas); era un proceso predominantemente escrito, con actuaciones judiciales dilatadas, sin inmediación $-\mathrm{o}$, mejor dicho, sin que esta fuera utilizada-. Ello no quiere decir que en el proceso de la Nueva Ley Procesal del Trabajo no haya nada escrito, pues la presentación de la demanda y 
la contestación son escritas; pero en el antiguo, todo o casi todo era escrito y esto lo hacía lento. $\mathrm{Si}$ a lo anterior le sumamos la manera en que a las partes se les notificaban los actos procesales - las notificaciones también eran escritas, pasaban por una central de notificaciones y, como consecuencia, podían demorar, en el mejor de los casos, treinta días hábiles-, queda claro que el antiguo sistema no ayudaba a la celeridad del proceso. Por ello, para que existiera un cambio real tendría que darse una reconfiguración del proceso como Nueva Ley Procesal del Trabajo, que tiene esta lógica de proceso abreviado, y el proceso ordinario, que concentra una serie de etapas y permite un proceso bastante más célere; sumando a todo ello la figura de las notificaciones electrónicas, que también ha sido un aspecto fundamental en este cambio.

Otra característica importante del nuevo proceso es la prevalencia de lo oral sobre lo escrito, sobre lo cual Michael Vidal ya había apuntado cosas interesantes. Por ejemplo, la posibilidad o no de realizar el cambio de pretensiones a lo largo del proceso, me trae a la memoria algunas situaciones en las que he podido participar. Hubo un proceso en el que la demandada afirmaba, en su contestación, que el demandante no era su trabajador; pero luego, en el devenir de la audiencia, reconoció lo contrario, hecho que el juez consideró como una actitud temeraria o de mala fe, por lo que procedió a multarla con cinco unidades de referencia procesal por presentarse al proceso y no decir los hechos tal cual habían ocurrido en la realidad.

Otra característica que he advertido es que hay un potenciamiento y control del proceso por parte de los jueces. Hoy en día los jueces, por decirlo de alguna forma, son los directores de orquesta; están premunidos de todas las facultades y herramientas - como las multas y la ayuda tecnológica que facilita gravar en audio y video las audiencias - y dejan de lado los formalismos (existe la posibilidad de que el juez haga preguntas en cualquier momento), todo lo cual les permite ser los directores del proceso y poder determinar en qué momento se realiza tal o cual actividad que considere necesaria para resolver el conflicto.

En el proceso de la Ley 26636 había una audiencia única, en la que existía una etapa de conciliación, luego de lo cual se llegaba a la actividad probatoria, etapa en la que se actuaba una declaración testimonial o de parte, una revisión de pericia o de documentos, con lo que se generaban dilaciones. En el nuevo proceso sólo hay un momento en el que las partes pueden probar los hechos que alegan, y es en la audiencia de 
juzgamiento; no hay otra oportunidad. Es en ese momento donde debo convencer al juez de mi posición, con la actividad probatoria que yo debo desplegar de cada uno de los medios probatorios que sustentan mi teoría del caso.

Asimismo, ya se había tocado el tema de la presunción de laboralidad, que se relaciona con la actividad probatoria. En efecto, ahora la Nueva Ley Procesal del Trabajo cambia las reglas de juego sobre la manera de probar la existencia de una relación laboral (carga de la prueba). Antiguamente, había que probar la existencia de una relación laboral, es decir, determinar si existen o no los elementos típicos de una relación laboral: analizar si hay remuneración, subordinación y todos esos elementos que normalmente serían materia de probanza. La presunción de laboralidad supone todo un cambio en la forma de defenderse por parte de las empresas y una forma distinta de interponer demandas. He visto, por lo menos en la práctica, que las reglas o las fórmulas y la lógica de defensa de las empresas cambia, de una forma reactiva a una forma activa. Debo analizar cuáles son mis ámbitos de conflictividad, debo analizar zonas grises, así como con qué medios de prueba cuento para poder afrontar un proceso de esta naturaleza. Entonces, la aplicación de la Nueva Ley Procesal del Trabajo ha ocasionado un cambio en la lógica de defensa de las empresas y, también, en la parte demandante.

¿Qué defecto y novedades podemos encontrar? En principio, quisiera señalar que comparto la exposición de Michael Vidal. Es cierto que la Nueva Ley Procesal del Trabajo tiene aciertos y desaciertos. Sin embargo, la sensación que tengo de las ocho o nueve cortes en donde he podido litigar es que los jueces, en su mayoría, han hecho el mayor esfuerzo para que la norma se implemente de la mejor manera, aunque hay temas pendientes, como la capacitación y la gestión procesal. En esa línea, es importante mencionar que en distintas cortes hay grupos de jueces que se han estado reuniendo para resolver algún punto no muy claro referido a la aplicación de la nueva ley. Es como decir: "No tenemos recursos, pero nos reunimos y tratamos de llegar a un consenso para poder darle a la ciudadanía prioridad sobre la forma de encarar un determinado proceso". Otro ejemplo de este compromiso lo da la Corte Suprema, que este año ha emitido un pleno jurisdiccional laboral donde ha analizado una serie de tipos de procedencia de procesos que, en realidad, la gente no los tenía muy claros. Incluso había ciertos temas en 
conflicto con el Tribunal Constitucional, como la figura del despido fraudulento, incausado, que el pleno jurisdiccional laboral ha resuelto y ha mencionado que los juzgados laborales son competentes para ver ese tipo de procesos. Todas estas actuaciones por parte del Poder Judicial no hacen sino evidenciar su compromiso con la correcta aplicación de la nueva ley.

Lo cierto es que esta norma ya llegó, trayendo un cambio radical en la forma de ver y analizar el proceso laboral; y si bien contiene aspectos que no están muy claros, pienso que se van a ir resolviendo en la práctica. Un ejemplo de ello es que en los primeros años de aplicación -2010 y 2011 - había incógnitas tan simples como: si asisto a la audiencia de juzgamiento y allí me percato de que no se había pagado la tasa por ofrecimiento de pruebas, ¿qué hago?, ¿suspendo la diligencia? Esta simple pregunta evidencia que aún estamos premunidos de la ley antigua, porque en el esquema de la nueva ley dicho supuesto es impensable, pues las audiencias tienen que llevarse a cabo de todas formas, y si existiera una falta administrativa - como no haber cumplido con el pago de un arancel judicial por ofrecimiento de pruebas-, ello no debería generar demoras ni suspensiones de diligencias. Esto nos lleva a ver que todavía hay algunas acciones que se rigen por la antigua ley, no solo por parte de los magistrados, sino de los propios abogados. Era increíble, pero los abogados llegaban a la audiencia con la intención de suspenderla diciendo que no se había pagado la tasa, hecho que debería ser catalogado como mala fe procesal. Lo cierto es que esta nueva ley implica otra forma, otra visión de los procesos y de otorgar una tutela jurisdiccional efectiva, que realmente sea adecuada para las partes. Recomendaría contar con un bagaje documentario que permita afrontar este tipo de procesos. En mi caso, normalmente defiendo empresas, por lo que recomiendo que tengan un sistema informativo que les permita afrontar este tipo de procesos en forma inmediata. Ya no puede haber disociación entre empresa y abogado, donde la empresa le pasaba la demanda al abogado y este, en algunos casos, se la pasaba al asistente y/o practicante. Hoy en día se requiere mucha dedicación y trabajo constante entre empresas y abogados, con canales seguros de comunicación y con la información necesaria para afrontar el proceso.

Otra recomendación es analizar las zonas de conflicto, pues todo proceso tiene como inicio un conflicto, y un conflicto no resuelto. Si analizamos cuáles son los conflictos que se pueden generar en una 
determinada empresa y podemos atacarlos, en el buen sentido de la palabra, ello coadyuva a que la conflictividad del proceso sea menor, a tener trabajadores más felices, más contentos $\mathrm{y}$, como consecuencia de ello, menos procesos. Entonces, es una cuestión que parece muy simple, pero que algunas empresas no la tienen muy clara.

Otra clave es anticiparse, lo que va mucho de la mano con analizar conflictos. Cómo me anticipo, qué necesito. Necesito tener canales de comunicación adecuados entre los trabajadores y la empresa, para poder determinar cuáles son sus necesidades, cuál es su pensamiento, qué es lo que realmente quisieran de la empresa, para así poder buscar sinergias y minimizar las posibilidades de conflicto.

En líneas generales, la Nueva Ley Procesal del Trabajo no solo genera una tutela jurisdiccional efectiva real, pues introduce un proceso más célere. La aplicación de principios ocasiona todo un cambio de mentalidad respecto a los temas laborales, y las actuaciones de las partes también han variado. Como se ha mencionado, es muy difícil que un abogado, hoy, se pare ante a un juez y diga - con la posibilidad de que la grabación salga en YouTube-: "No es mi trabajador", cuando está probado con documentos, con grabaciones, con declaraciones, que sí lo es. Esas situaciones, definitivamente, no resultan defendibles hoy en día, y el abogado termina perdiendo credibilidad. Son vicisitudes que deberían tomarse en cuenta antes de defender un caso: analizar, primero, si se puede ganar, y si no se puede ganar, recomendarle al cliente conciliar.

La norma es bastante positiva. Hay todavía muchos temas por ver y de seguro habrá muchos inconvenientes en el camino, pero lo cierto es que la norma ya está siendo aplicada y ha venido a serlo en un momento en el que el país está en crecimiento. Es hora de que se reivindiquen de alguna forma los derechos de los trabajadores, de que se analice si hay algunos focos de conflicto, de si hay necesidad de ellos y de poder cumplir con las normas laborales, evitando conflictos innecesarios que nos lleven mañana o más tarde a un proceso de esta naturaleza.

\section{Germán Ramírez-Gastón}

Agradecemos la excelente exposición de Eduardo Mercado, donde nos recuerda que la justicia tardía no es justicia y señala que los procesos contemplados bajo la Ley 26636 duraban un promedio aproximado de 
cinco años y se prevé que con la aplicación de la Nueva Ley Procesal del Trabajo no deberán durar más de doce meses.

Cabe acotar que la nueva ley ha previsto el proceso abreviado, de una sola audiencia, donde la sentencia se dicta una hora después de realizada esta última, con lo cual los abogados vamos a tener que esperarla junto con los clientes.

Lo mismo sucede en el proceso ordinario, con la diferencia de que habrá dos audiencias: la primera, de conciliación, y la segunda, de juzgamiento, luego de lo cual se dictará sentencia en sesenta minutos, salvo que el juez se reserve la posibilidad de pronunciarla dentro cinco días.

Esta nueva circunstancia obligará a los abogados a rediseñar la estrategia de defensa, y permitirá darle al cliente un nuevo alcance de cómo enfocar la conflictividad a fin de evitarla, anticiparse al conflicto, buscar sinergias y minimizar las contingencias.

Eduardo Mercado también nos ha recordado que la invitación a conciliar es un momento que no es grabado y que en el nuevo proceso laboral se han previsto sanciones para las partes y los abogados por temeridad procesal.

También nos ha hablado sobre la carga de la prueba, refiriéndose a la presunción de laboralidad y a la dificultad de desvirtuarla.

Finalmente, ha mencionado la necesidad de implementación de consensos y plenos jurisdiccionales, recordando que por el momento existen dos competencias: una para el ámbito la Ley 26636 y otro para la nueva Ley 29497. Ha señalado que en cuanto a la primera, procede la pretensión de reposición por despido incausado y fraudulento en la vía ordinara laboral, a cargo de los juzgados especializados de trabajo; en cambio, con la Ley 29497, dichas pretensiones deben dilucidarse en el proceso abreviado laboral, si la pretensión es planteada como única.

En conclusión, a través de su brillante exposición y comentarios nos recomienda anticiparnos a los conflictos y diseñar nuevas estrategias de defensa para minimizar las contingencias.

A continuación, voy a ceder el uso de la palabra a Carlos Quispe Montesinos, juez especializado en lo laboral en la Corte Superior de Lima y docente de la Maestría de Derecho de Trabajo en la Universidad de San Martín de Porres. 


\section{Carlos Alberto Quispe Montesinos}

Buenas noches. Agradezco la gentil invitación para participar en esta mesa. La perspectiva que voy a expresar en mis intervenciones es la propia de mi condición de magistrado laboral.

La implementación del nuevo modelo procesal laboral, regulado por la Ley 29497, ha suscitado muchas expectativas, yo diría que demasiadas. Así, cuando la mencionada ley se promulgó en enero del 2010, en algún diario de circulación nacional se publicó como titular: "Revolución en la justicia laboral: los procesos que duran muchos años, ahora durarán seis meses".

La Nueva Ley Procesal del Trabajo está vigente en catorce distritos judiciales, de los treinta y uno en los que se encuentra organizado el Poder Judicial, y el 5 de noviembre - en unas semanas - también lo estará en el distrito más grande: Lima. En estos dos años del nuevo modelo, en aquellos distritos judiciales donde ya rige, la esperada duración de seis meses de los procesos se dio en un principio, pero ahora ya no. Por ejemplo, la semana pasada, es decir en octubre del 2012, estuve con un grupo de magistrados en la ciudad de Trujillo - que pertenece a la Corte Superior de Justicia de La Libertad-, lugar en el que está funcionando mejor el nuevo modelo procesal; sin embargo, las audiencias están siendo programadas para ser desarrolladas luego de un periodo de seis meses desde la ocasión de su programación.

La estructura del nuevo proceso implica: presentación de la demanda, calificación, citación de las partes a una audiencia de conciliación y, luego de ello, si no se concilia, cita a una segunda audiencia, denominada de juzgamiento. En la corte judicial que he mencionado, las audiencias de conciliación se están programando, aproximadamente, a seis meses de la interposición de la demanda; es decir: lo que teóricamente iba a durar todo el proceso, y ello sólo para el desarrollo de la primera audiencia. Esto se debe a que la oralidad necesita condiciones, y una de ellas es una carga adecuada.

Actualmente, la carga promedio de los juzgados especializados de trabajo de la Corte Superior de Justicia Lima - donde todavía no está vigente la nueva ley- es de 1.222 expedientes por juzgado. En 1996, con la entrada en vigencia de la Ley 26636, Ley Procesal del Trabajo, se hizo un estudio y se determinó que la máxima carga que podría tener un juzgado laboral para resolver los procesos, en los plazos previstos por esa norma, era de 600 expedientes. Ahora, a puertas de la entrada en 
vigencia de la nueva ley, tenemos el doble de esa carga, exigiéndose una mayor dedicación por parte de los jueces para cada proceso. Ello porque, primero, en la nueva estructura del proceso se ha previsto una audiencia de conciliación, solo para que el juez agote la posibilidad de resolver pronto la controversia, lo que es un mérito de la ley; y segundo, si el proceso no termina en la audiencia de conciliación, el juez, en la audiencia de juzgamiento - en una sola diligencia-, tendrá que actuar todos los medios de prueba, escuchar los alegatos verbales de los abogados y expedir el fallo de inmediato o, eventualmente, en el peor de los casos, reservar el pronunciamiento para cinco días. Es evidente que la dedicación que hay que darle a cada proceso para conciliarlo o bien para prepararlo debidamente a fin de expedir la decisión final, requiere mucho más tiempo.

En el esquema procesal de la Ley 26636 se ha previsto una audiencia única, en la que se desarrollan las etapas de saneamiento, conciliación, fijación de puntos controvertidos y actuación probatoria, todo ello en un tiempo que va de cincuenta minutos a una hora. Ello es así debido a que la carga procesal superior a los 1.000 expedientes hace que el juez no le pueda dedicar mucho más tiempo al desarrollo de las audiencias. Así, una de las condiciones de la oralidad es contar con una carga procesal adecuada, a la que un juez pueda dedicarle el suficiente tiempo que requiere poner fin a un proceso. El nuevo proceso laboral exige, entonces, tener pocos expedientes y contar con una eficiente organización judicial.

La oralidad, así como requiere una carga adecuada, también exige más jueces que los normalmente previstos. En la Corte Superior de Justicia de Lima hay, bajo la Ley 26636, 29 juzgados especializados permanentes y 6 juzgados de descarga (es decir, 35 juzgados), que tienen un promedio de 1.222 expedientes, atrasados, pues los procesos no se desarrollan en los plazos legalmente establecidos. Se ha previsto, con la implementación de la Nueva Ley Procesal del Trabajo en Lima, que inicialmente operen 16 juzgados especializados de trabajo, es decir, menos juzgados que los que operan bajo el esquema anterior. Por lo tanto, puede observarse que las condiciones previstas como carga adecuada y número de jueces suficiente no se están cumpliendo al inicio. Ciertamente, la organización judicial requiere de recursos; por ejemplo, para cumplir una previsión de la nueva ley, se necesita la implementación de un fondo de formación de magistrados; habilitar ambientes 
adecuados; salas de audiencia en donde haya grabaciones de audio y video; equipos de tecnología de información que permitan grabar, almacenar y conservar el desarrollo de las diligencias; y una red electrónica de notificaciones, de la cual se ha hecho referencia. Ese es un primer punto: un sistema oral requiere de condiciones mínimas que deben ser satisfechas para que, en efecto, se cumplan aquellas finalidades que justifican la implementación de tal esquema procesal.

En cuanto a las ventajas y novedades, un aspecto importante es el fortalecimiento de la conciliación. Veamos un dato. En el 2012, entre enero y julio, el promedio de conciliaciones en los procesos laborales desarrollados bajo la ley 26636, en los juzgados especializados de la Corte Superior de Lima, ascendió a 0,4\% por juzgado; es decir, en promedio se logra, en los procesos regulados bajo la ley procesal que aún rige en Lima, menos de una conciliación mensual por juzgado. Ello se debe a que el juez no dedica mucho esfuerzo para conciliar y las partes -fundamentalmente, la demandada - tampoco quieren poner fin a la controversia mediante la conciliación, no existiendo incentivos suficientes para conciliar ni desincentivos para que el demandado se mantenga en situación de incumplimiento.

El nuevo modelo procesal laboral fortalece la conciliación, y los resultados los tenemos a la vista. En Latinoamérica, el primer país en el que se implementa un modelo procesal laboral oral es Venezuela, en el 2002, y los venezolanos resaltan - con justa razón - que sus niveles de conciliación bordean el $90 \%$ de sus procesos: se concilia en casi todas las controversias y muy pocos procesos llegan a la etapa de juzgamiento. En el caso de Chile, su modelo procesal laboral basado en la oralidad es implementado en el 2007, y sus niveles de conciliación se encuentran en alrededor del 60\%, lo que también es plausible. Les decía que en el Perú, de los distritos judiciales en los que se encuentra vigente la nueva ley, en donde mejor está funcionando el modelo es en La Libertad, lugar donde, en el 2011, el nivel de conciliación llegó al 45\% de los procesos, lo cual es excelente. Este año, los niveles de conciliación se han reducido, en la indicada corte, a un $19 \%$, promedio que aun así sigue siendo bueno en comparación con los niveles de conciliación alcanzados en el modelo procesal regulado por la Ley 26636. Algo que se debe destacar, entonces, es que luego de calificada la demanda, en el acto procesal siguiente - que es la audiencia de conciliación - pueda concluir, pronto, la controversia. 
En cuanto a la simplificación de la actividad probatoria, la Nueva Ley Procesal del Trabajo establece una nueva carga probatoria, más precisa que la del modelo anterior, y ahora - como señala Mario Pasco - es el empleador el que debe probar que ya pagó, que no debe o que la obligación ya se extinguió. La carga de la prueba recae en el empleador, hasta el punto de que se ha previsto una presunción de laboralidad, en donde el trabajador sólo tiene que probar que prestó servicios y se presume que existe una relación de trabajo, siendo el empleador quien debe desvirtuarla.

Vinculado al tema de la carga de la prueba se encuentra el de la actuación probatoria, la cual se realiza en un único momento. Las partes deben ir a la audiencia de juzgamiento con toda la documentación y todos los medios de prueba, incluso con los testigos, peritos y cualquier medio que quieran hacer valer en el momento de la actuación probatoria, pues si no se presentan en esta ocasión, es muy probable que no puedan ser admitidos en el proceso.

Una de las situaciones reiteradas bajo la vigencia de la Ley 26636 ha sido que para efectuar una revisión documental, el juez le dice a la parte demandada: "Necesitamos ver su libro de planillas y las boletas, para determinar si se le ha pagado al trabajador", ante lo cual el empleador responde: "Bueno, señor juez, envíe un perito a la empresa y le daremos todas las facilidades". Ello implica que un servidor del Poder Judicial acuda a la empresa, realice una transcripción y luego regrese al juzgado para que realice un informe pericial; ergo, el Poder Judicial - en este caso, el juzgado laboral- le hace el trabajo probatorio al empleador. Eso se simplifica notablemente en la Nueva Ley Procesal de Trabajo, pues con esta norma es el empleador quien tiene que presentar, en ese único acto que mencioné - la audiencia de juzgamiento-, la documentación requerida. Por ejemplo, en la Corte de La Libertad han adoptado una práctica no expresada en la ley, pero que es eficiente, que es requerir a las empresas que la información referida a remuneraciones de los trabajadores sea presentada en un CD. Ya no existe un informe revisorio, en el que el perito tiene que recoger la información, compendiarla y transcribirla, sino que la empresa la presenta en un $\mathrm{CD}$, con lo cual es más fácil trabajar, pues se simplifica notablemente, en tiempo y en esfuerzo, la actividad probatoria, que es fundamentalmente documental.

Podemos señalar, también, que el nuevo modelo procesal exige que las demandas sean claras, precisas y documentadas. La experiencia nos 
permite afirmar que, en muchos casos, la defensa de los trabajadores no es la más especializada, prolija ni esforzada; por ello, muchas veces nos encontramos con demandas imprecisas o incompletas, en las que ni el juzgador ni la parte demandada tienen la certeza de qué es exactamente lo que se está demandando. Un modelo procesal por audiencias requiere contar con un escrito de demanda y uno de contestación muy claros, para, a partir de ello, efectuar las actuaciones orales. Ello se encuentra vinculado al desarrollo de conocimientos, habilidades, aptitudes y experiencias nuevas, para todo cual los abogados no hemos sido formados. La oferta educativa debe satisfacer, entonces, nuevos requerimientos, referidos a competencias con las que necesariamente deben contar los nuevos abogados en materia de litigación oral, redacción, argumentación, planteamiento de teorías del caso; materias en las que, por ejemplo, quienes nos encontramos en la mesa no hemos sido formados, pero son muy necesarias en un esquema procesal oral. Por ello, también las instituciones educativas tienen retos que asumir como consecuencia de este modelo procesal.

Algo importante que se observa, además, es la legitimación del juez. Yo he escuchado, y me lo han dicho: "Señor juez: ¿cuándo le proyecta la sentencia su especialista?", lo que a mí me afecta en lo particular, pues las sentencias las hago yo, y si en algún caso el asistente me prepara un proyecto, lo reviso y la sentencia nunca es idéntica a este, sino que siempre incorpora mis correcciones o modificaciones. Por eso, si el juez, en la audiencia de conciliación, ve que las partes se están acercando y saca un lapicero o una máquina y hace los cálculos pertinentes, ellas perciben que aquel domina el caso. Si el juez, en el momento que termina la actuación probatoria, expide el fallo, ciertamente está siendo legitimado ante las partes, pues ellas están apreciando en forma directa que quien decide es él y que no habrá momento extrajudicial en el que se favorezca a alguna de las partes. Un esquema procesal oral exige una debida preparación del caso porque el juez sabe que, terminada la audiencia de juzgamiento, debe poner en conocimiento de las partes su decisión, por lo que tiene que ir con el caso debidamente estudiado a efectos de que pueda expedir la decisión que fijará si corresponde o no estimar la demanda o si esta es fundada en parte. Ello, por cierto, mejora la percepción del juez por parte de quienes intervienen en la diligencia.

Respecto al tema de la prescindencia de las notificaciones, un factor que dilata de manera seria el desarrollo de los procesos judiciales es la 
notificación física de las resoluciones. En el proceso regulado bajo la Ley 26636, toda decisión que expide el magistrado ante un requerimiento de las partes implica que a través de un sistema lento e ineficiente se dirija una cédula al domicilio que ha sido fijado por el demandante o el demandado, siendo necesario esperar el retorno de los cargos, para tener certeza de que la notificación se produjo. Hay ocasiones en las que la cédula, acompañada de la resolución, se dirige a un domicilio distinto del fijado, lo que determina la necesidad de notificar nuevamente. En el nuevo proceso laboral, en la etapa de cognición del proceso, lo único que se notifica por cédula, de manera tradicional, es la demanda. El juzgado recibe la demanda, esta es calificada y la resolución se notifica a la parte demandada, la cual acude a la audiencia de conciliación y, si se concilia, concluye el proceso. Si no se concilia, en ese momento la parte demandada presenta su escrito de contestación de la demanda, el que es revisado por el juez, quien lo califica y se lo entrega al demandante, por lo que ya no hay necesidad de notificarle por escrito esa contestación. En la misma ocasión, el juez indica directamente a las partes la fecha y hora en que se producirá la audiencia de juzgamiento, por lo que ya no resulta necesaria la emisión de ninguna cédula.

Del mismo modo, terminada la etapa probatoria en la audiencia de juzgamiento, el juez comunica su decisión en forma verbal a las partes e indica en qué ocasión, dentro del término de cinco días, se expedirá la sentencia por escrito, pero no para que se emita una cédula, sino para que concurran en una fecha y hora exactas a fin de recoger su sentencia. Por lo tanto, la necesidad de efectuar una notificación tradicional desaparece, y esto es un mérito del nuevo esquema procesal.

También es necesario indicar los límites del nuevo modelo procesal laboral. Les había dicho al inicio que los procesos laborales normalmente son resueltos a partir de prueba escrita. En el 90\% de los casos, lo que se requiere en un proceso laboral es una prestación de dar suma de dinero, y si bien es cierto también se exige tutela frente a una posible afectación de derechos fundamentales - en los supuestos de trabajo en sobretiempo, descanso remunerado, estabilidad del empleo, participación en las utilidades, entre otros-, muchas veces, también en estos casos, la pretensión del trabajador se expresa en el pago de cierta cantidad de dinero - por horas extras, por vacaciones, por indemnización debido a despido arbitrario, o por utilidades, respectivamente-. El petitorio implica una cuantificación económica, y determinar si se debe 
o no se debe implica tener certeza de la base de cálculo, lo que exige una revisión documental. Entonces, tenemos una observación: ¿qué tan compatible es un esquema oral, en donde se privilegia la declaración de las partes, testigos, peritos y terceros, con una actuación probatoria que es, básicamente, documental? Si un empleador no pagó, así en la audiencia de conciliación su abogado argumente muy bien y pretenda hacer "decir" a los documentos una situación distinta de la realidad como que se cumplió con el pago, pero eso no es así-, poca trascendencia tendrán las actuaciones orales, pues una adecuada valoración permitirá concluir que no se efectuó dicho pago. Creo, entonces, que existe un sobredimensionamiento de la importancia de las declaraciones en el nuevo proceso.

Les había mencionado que el juez, por las exigencias del nuevo modelo, al concluir la audiencia de juzgamiento expide la decisión que resuelve la controversia. Esto hace necesario que se prepare debidamente y acuda a la audiencia con una decisión formada sobre el caso. Es decir, a partir de la demanda, el contenido de la contestación y el análisis de los medios probatorios - todo ello, previo al desarrollo de la audiencia - , el juez ya tiene una idea de a quién le corresponde la razón y eso lo tiene que saber muy bien porque, terminada la audiencia de juzgamiento, debe dar su fallo. Si ello es así, en muchos casos la actuación probatoria servirá, en realidad, para corroborar una decisión que previamente el juez ya ha adoptado. Habrá casos en los que, sin duda, dicha actuación lleve a que el juez reformule su decisión, la deseche o elabore, en ese momento, una decisión distinta. Estimo que, casi siempre, debido a la naturaleza de las pretensiones que se pretenden hacer valer en un proceso laboral - tutela frente a un incumplimiento de la contraparte-, el juez, luego de la actuación probatoria, corroborará una inicial decisión adoptada a partir de una inicial revisión documental efectuada con anterioridad a la diligencia.

Se dice mucho que la oralidad en el proceso hace que el juez, a partir de las declaraciones de las partes, de su desenvolvimiento y de cómo afrontan las interrogantes, pueda darse una idea de a quién le corresponde la razón; esto es, que haga una valoración a partir de la autoafirmación, inseguridades, dudas o titubeos de los declarantes. Algunos han calificado esto como "el mito del juez psicólogo" y, en efecto, nos encontramos ante un mito, pues el juez no tiene formación profesional para percatarse, a partir de cómo responde alguien a una interrogante o 
de cómo se expresa, si su testimonio es verdadero o no. Aun si el juez se percatara de las referidas manifestaciones psíquicas de los declarantes, habrá problemas para fundamentar una decisión sobre la base de percepciones o expresiones subjetivas.

En cuanto a la publicidad del proceso, también se ha dicho que la oralidad la garantiza. Normalmente, a una audiencia de juzgamiento - salvo las partes y, a lo mejor, alguien interesado en el desarrollo del proceso- no van muchas personas. La presencia de quienes no están vinculados a un proceso específico se da, pues, en esta etapa inicial, en la que el nuevo modelo se está implementando, pero no necesariamente en todos los procesos. La publicidad puede garantizarse debidamente mediante la digitalización del proceso, su difusión por internet, como ahora se hace a través de la página del Poder Judicial, en donde aparece un reporte de los principales actos del proceso. Asimismo, si hay audiencias que han sido grabadas, ayudaría que estuvieran digitalizadas, pues de ese modo se podría acceder a ellas y no necesariamente concurriendo. Oralidad y publicidad no van necesariamente de la mano. La digitalización, los medios masivos, internet y las redes sociales pueden facilitar de alguna forma la publicidad del proceso.

Recordemos nuestras clases de procesal, cuando se presentan de manera didáctica las etapas del proceso: etapa postulatoria, probatoria, decisoria, impugnatoria y de ejecución. Podríamos señalar que la concentración que permite esta estructura del modelo procesal oral se restringe a las tres primeras etapas: la postulatoria, donde se presentan la demanda y su contestación; la probatoria, que se realiza en una sola diligencia; y la decisoria, donde la sentencia se expide apenas termina la etapa probatoria. Sin embargo, podemos preguntarnos: ¿qué previsiones ha tomado la nueva norma en lo que concierne a la etapa de ejecución? Conversaba con un colega de Chile - en la región, el país donde la oralidad está funcionando mejor-, y este me señalaba que la oralidad ha determinado procesos significativamente más cortos en la etapa de declaración del derecho, pero más largos en la etapa de ejecución, pues, si se expide la sentencia y el demandado no cumple, hay que recurrir a las habituales medidas de ejecución forzada - la que es enteramente escrita - y ello puede devenir en que tengamos procesos cortos respecto a la declaración del derecho, pero significativamente extensos en la etapa de ejecución de la decisión. Es entonces evidente la ausencia de la oralidad en la etapa de ejecución de las decisiones. 
A partir de lo dicho puede apreciarse que la implementación de un modelo oral exige condiciones importantes: mayor número de jueces, adecuada carga procesal y determinadas acciones derivadas de una política judicial. El nuevo modelo presenta fortalezas y bondades, pero también limitaciones. La oralidad no es la solución de todos los problemas que se presentan en la justicia laboral, y muchas de las innovaciones de la Nueva Ley Procesal del Trabajo no necesariamente derivan de aquella. Por ejemplo, se ha ampliado en forma sustancial el ámbito de competencia de la justicia laboral y se ha determinado que la justicia de paz letrada debe ser especializada, pues hasta ahora los jueces de paz letrados eran "todistas" - es decir, tenían que resolver conflictos de naturaleza penal, civil, laboral y familiar-, y, cuando uno es "todista", normalmente no es especializado en ninguna materia. Una de las fortalezas de la nueva ley es que ahora se crean juzgados de paz letrados especializados en lo laboral, con lo que desde el primer nivel de la judicatura ya tenemos jueces especialistas, lo cual representa mayores garantías en lo concerniente a la impartición de justicia. Hay también mejoras en las reglas de distribución de la carga de la prueba y en la tutela cautelar, como la creación de tribunales unipersonales que, dentro de las salas laborales, resuelven determinadas controversias en última instancia. Es decir, el nuevo modelo muestra una serie de bondades que, aunque no necesariamente son expresión de un esquema procesal oral, constituyen importantes innovaciones en la gestión de los procesos.

Puedo afirmar que el nuevo proceso laboral es mucho más que oralidad; estamos ante un esquema con fortalezas - las hemos señaladoy que requiere condiciones que pueden y deben ser cumplidas. Ellas deberían hacer posible que llegáramos a contar con procesos eficientes, es decir, juicios que garanticen decisiones justas, céleres y efectivas, para resolver conflictos en justicia, brevemente y en los que la decisión se cumpla pronto y no constituya una declaración difícilmente ejecutable. Para ello se requiere el compromiso de los actores judiciales, lo que implica a jueces, abogados y, en cierta manera, a las universidades (respecto a la formación de las personas que asumirán estos roles en el ámbito laboral). Si ello se cumple, y asimismo las condiciones, podemos tener la esperanza de juicios eficientes y superar estos procesos, cuyos defectos, deficiencias y excesiva duración han determinado la necesidad de optar por un modelo como el que se reconoce en la Nueva Ley Procesal del Trabajo. 


\section{Germán Ramírez-Gastón}

Muchas gracias, doctor Quispe Montesinos, por transmitirnos en sus comentarios su valiosa experiencia en el ámbito judicial.

Es evidente que la carga procesal siempre ha sido un aspecto clave, y quién mejor que usted para decir que encargarse de 1.222 procesos en un solo juzgado resulta excesivo. Esperamos que en un futuro cercano la carga asignada sea más razonable y la cantidad de jueces que se aboquen al manejo de la Nueva Ley Procesal del Trabajo sea suficiente, pues aunque el proceso tomará más tiempo en el desarrollo de las audiencias, será más corto en la espera de una resolución que le ponga fin.

Como usted bien señala, el fortalecimiento de la conciliación es una pieza clave dentro del nuevo proceso. Ojalá que sus predicciones sobre dicho medio de solución de conflictos se cumplan, para beneficio de los litigantes y la administración de justicia.

El nuevo modelo de demanda va a exigir que esté bien redactada, lo que a su vez va a requerir una mejor preparación de abogados, litigantes, organizaciones sindicales y estudiantes de derecho.

Si bien el principio de oralidad consagrado en la Nueva Ley Procesal del Trabajo puede resultar, para algunos, novedoso, debo recordar que los procedimientos previstos en los Decretos Supremos 007-71-TR y 03-80-TR - ya derogados - contenían también los principios modernos del derecho procesal laboral, como la oralidad, la sencillez, la concentración, la economía procesal, la inversión de la carga de la prueba, entre otros, los cuales fueron modificados por la Ley 266136 al establecer un procedimiento con mayor énfasis en lo escrito.

Recuerdo que bajo la vigencia de los dispositivos derogados, la contestación de la demanda se presentaba por escrito en el mismo acto de la audiencia o acto de comparendo, lo que implicaba una desventaja para el trabajador o sindicato, pues, en el mismo acto, no solo debían leer y tomar conocimiento de la contestación en pocos minutos, sino formular toda clase de incidentes, tachas, impugnaciones $\mathrm{u}$ oposiciones sobre las pruebas aportadas por el empleador, lo que exigía, además del uso de la argumentación oral, cierto grado de preparación para enfrentar una estrategia de defensa en el acto del comparendo, acto donde, a su vez, la parte demandada debía absolver el trámite de modo oral. Todo esto quedo sin aplicación con la promulgación de la Ley 26636. 
Con la vigencia de la Nueva Ley Procesal del Trabajo, Ley 29497, se rescata el principio de oralidad, otorgándosele mayor importancia que en las normas anteriores - esta vez con el auxilio de los medios audiovisuales - y haciéndolo determinante en la solución del conflicto. Ahora las partes tendrán que estar muy preparadas para la confrontación de posiciones, a fin de exponer claramente los hechos, formular cuestiones litigiosas y ofrecer los medios probatorios correspondientes, además de formular preguntas verbalmente, ofrecer pruebas y formular alegatos en la audiencia de juzgamiento.

Los jueces, a su vez, deberán emitir su fallo después de sesenta minutos de finalizada la audiencia, salvo en casos excepcionales, donde pueden reservarse hacerlo dentro de unos días. Esto en la práctica los llevará a estudiar con antelación el caso, con la posibilidad de asumir posiciones o prejuzgamientos que podrán ser corregidos en el proceso según la capacidad de persuasión de los abogados litigantes y de las partes dentro de un proceso oral.

La ventaja de la oralidad permite descifrar qué está detrás de la demanda o de la contestación escrita, produciéndose una imagen real de cuál es el conflicto y cómo debe resolverse.

Por último, no quisiera dejar de recordar que el doctor Quispe nos ha hablado de la importancia de la concentración de las etapas. Sin embargo, basado en su experiencia, nos señala un grave problema y deja una inquietud para la ronda de preguntas: ¿qué pasará con el problema de la ejecución de la sentencia?

A continuación, cedo la palabra a la doctora Cynthia Briceño.

\section{Cynthia Briceño Jiménez}

Buenas noches, y gracias por la invitación. En mi ponencia intentaré explicar y responder cada una de las preguntas y puntos que se han planteado sobre la Nueva Ley Procesal del Trabajo, pero empezaré por remarcar, de manera rápida, algunos aspectos que se trataron en las exposiciones que me precedieron, a fin de poder dar mi punto de vista.

El primer punto se relaciona con la oralidad y la celeridad. Respecto a esto, surge la pregunta: ¿qué tan viable es que el proceso laboral sea oral y rápidamente expeditivo? La respuesta depende, básicamente, de que la oralidad se convierta en una característica del proceso laboral, pues recordemos que implica dinamismo, lo cual no se logra sólo con el 
uso de la palabra al hablar, sino que tiene que ver con el principio de concentración, el que - junto con la determinación, la celeridad, la economía procesal, la veracidad y la publicidad - forma parte del proceso laboral que se ha plasmado en la Nueva Ley Procesal del Trabajo. En ese sentido, la oralidad debe ser entendida como un modo de actuar de los operadores judiciales, de los usuarios y de los que acceden a la justicia.

Pero además se necesitará de la existencia de la justicia laboral, la que, igualmente conminada con determinados valores y principios, hará viva la oralidad; por ejemplo: la prevalencia del fondo sobre la forma, la participación de las partes y sus abogados (en las audiencias) y la preparación de los jueces. En su momento, el magistrado Carlos Quispe mencionó cuál ha sido la preparación y cómo vienen abocándose los jueces a los nuevos procesos laborales. Además de ello, importan la participación de los abogados en las audiencias, la búsqueda de la verdad, la valoración razonada de la prueba, la razonabilidad de las decisiones adoptadas en el proceso, la preocupación por la igualdad efectiva de las partes, el respeto de las garantías constitucionales, entre otros aspectos. En consecuencia, en la medida en que la oralidad sea una característica del proceso laboral que hemos referido, este será expeditivo.

Considero que no debemos temer al cambio. Me gustaría mencionar que en Europa, por ejemplo, el juicio oral fue implementado desde fines del siglo XIX y durante todo el siglo XX, mientras que en nuestro entorno lo vienen haciendo cuatro países: Colombia, Chile, Ecuador y Venezuela. Incluso, en el presente año, en estos dos últimos países la oralidad viene siendo impuesta como un mandato constitucional.

El diario oficial El Peruano publicó un balance realizado por el Poder Judicial sobre la aplicación de la Nueva Ley Procesal del Trabajo, que resalta los logros de esta y el promedio de los juicios realizados con el modelo actual: cuatro meses sin conciliación y tres meses con esta, a diferencia de los largos años que tomaba el proceso laboral con la Ley 26636. Además, el tiempo de los procesos se habría reducido en un $77 \%$ : $67 \%$ en las salas superiores, $80 \%$ en los juzgados especializados y mixtos, y $75 \%$ en los juzgados de paz letrados. Entonces, puede verse que el resultado viene siendo favorable, aunque hay que tener cuidado de no caer en usos tradicionales, como el inmovilismo, que es lo que caracteriza o viene caracterizando a la aún vigente Ley 26636 y que, en cierta forma, es lo que iría en contra de la oralidad en el proceso laboral que se viene implementando en nuestro sistema. 
Otro aspecto que me parece importante es la presencia de dos elementos imprescindibles para que las empresas afronten con éxito un juicio. El primero: ajustar los procesos internos y la documentación en general para que sean factores positivos en el momento de litigar. Los documentos deben ser claros, es decir, no solo entendibles para la empresa o el trabajador, sino también para una persona ajena; en este caso, el juez. Si uno le presenta al juez documentos que no van a ser claros, eso finalmente puede ir en perjuicio de la parte que está litigando. El segundo elemento es que las empresas deben contar con un personal capacitado para coadyuvar de manera más eficaz en la defensa; en ese sentido, es importante la participación de los ejecutivos de la empresa, quienes deben estar preparados para las diversas preguntas que pueden hacer los jueces. Tuve la oportunidad de estar en una audiencia en donde uno de los abogados quiso presentarse como el apoderado de la empresa y el abogado de la otra parte lo cuestionó y pidió la presencia del representante legal de aquella. Como era de esperarse, el juez favoreció este pedido y pasó a tomar la declaración del jefe de Recursos Humanos de la empresa, como consecuencia del ofrecimiento de su declaración testimonial. Entonces, fue él quien actuó como representante en la declaración de parte y debía estar preparado para conocer la posición y los argumentos adecuados para hacer una defensa correcta.

El segundo punto que se planteó es el de la predictibilidad de las resoluciones y la confianza en los operadores de la nueva ley. Las preguntas son: ¿la nueva ley genera una mayor predictibilidad en las resoluciones? y ¿la nueva propuesta laboral genera confianza en los operadores? Para responder a cada una de estas interrogantes es preponderante la participación y la preparación del juez. Este debe tener una participación activa, pues debe tomar las riendas del proceso, evitando dilaciones injustificadas y, sobre todo, creando espacio para la verdad, la cual ya no estará escondida en una enorme cantidad de papeles. En esa medida, las resoluciones judiciales deben ser predecibles, los procesos laborales más breves y la respuesta más pronta. Con lo mencionado se podrá suscitar mayor confianza en los jueces, más aún cuando su actuación es mucho más visible con la Nueva Ley Procesal Laboral que con la anterior. Al decir que el proceso laboral debe ser más breve, no olvido que, evidentemente, este cambio (de proceso laboral largo a proceso corto) no se va a dar de un día para otro.

Vuelvo a resaltar la importancia de la capacitación de los jueces, y para ello existen instituciones como la Academia de la Magistratura, la 
Sociedad Peruana de Derecho del Trabajo y la Seguridad Social, entre otras que cumplen un gran rol en el espacio y formación de jueces y magistrados. Ahora bien, respecto a la predictibilidad de las resoluciones judiciales, cabe destacar el peso de la interpretación y la aplicación de los precedentes vinculantes del Tribunal Constitucional y de la Corte Suprema, que vienen siendo recogidas en el artículo 4 del título preliminar de la Nueva Ley Procesal del Trabajo. En la actualidad, el Ministerio del Trabajo y Promoción del Empleo - en colaboración con el Poder Judicial y el Tribunal Constitucional - ha implementado una base de datos pública y actualizada que permite a los jueces y litigantes acceder a la jurisprudencia y los precedentes vinculantes. Asimismo, y también con el fin de aumentar esa predictibilidad, a finales del primer semestre de este año se dio el primer pleno jurisdiccional supremo en materia laboral, donde se contó con la participación de los magistrados supremos de las salas de Derecho Constitucional, Social, Permanente y Transitoria. Este pleno se justificó por la necesidad de unificar y consolidar diversos criterios con los que fueron resueltos, en juzgados y salas, temas muy similares.

El tercer punto puesto sobre el tapete es: ¿qué tan bueno es que el tiempo de la tramitación de los procesos sea reducido como lo plantea la ley? Desde mi perspectiva, el sistema parece estar funcionando, pues se está resolviendo de manera más rápida, lo que no ocurría con los procesos anteriores, que demoraban años y años. Incluso, la idea de la sentencia dictada en una audiencia ha impulsado a muchas de las partes a profanar fórmulas conciliatorias, lo que en el sistema de la Ley 26636 se consideraba totalmente innecesario. Todo esto ha contribuido a tener procesos más breves y más satisfactorios para las partes; incluso, al analizar el resultado de las sentencias, nos percatamos de que la calidad de estas no ha bajado, a pesar del cambio en la tramitación en los procesos laborales. En cierta medida, hay que ser positivos con la nueva ley y no generarle anticuerpos antes de que sea implementada de manera integral.

El cuarto punto planteado tiene que ver con la opinión que merecen las casillas electrónicas. En febrero del 2001 se promulgó la Ley 27419, Ley sobre Notificación por Correo Electrónico, que facultaba a las autoridades judiciales a emitir las resoluciones del proceso judicial por correo electrónico; siete años después, el Consejo Ejecutivo del Poder Judicial, mediante la Resolución Administrativa 214-2008-CE, dispuso la implementación progresiva, a nivel nacional, denotificaciones electrónicas, 
las que pueden ser definidas como aquellas comunicaciones que emiten la Administración Pública y la privada usando medios electrónicos y telemáticos. En el campo de la administración de justicia son la alternativa inmediata para lograr mayor economía procesal, mayor celeridad y mayor seguridad en el proceso laboral. Las casillas electrónicas reducen el tiempo en la tramitación de los procesos y su aplicación en el país ha tenido buena acogida desde su nacimiento en el 2001; es más, tenemos conocimiento de que, a la fecha, superan los 2.800 registros.

El quinto punto planteado se relaciona con la pregunta: ¿es verdad que la nueva ley favorece la probanza del vínculo laboral? Que exista una presunción de laboralidad no coloca en un estado de indefensión a la parte demandada, ni implica que el demandante, por su sola afirmación, ya tenga el proceso ganado, pues igualmente tiene que acreditar la prestación de servicios, que esta prestación haya sido realizada por él y que haya existido un trato sucesivo y único. Evidentemente, ambas partes deben saber en qué casos es mejor recurrir a una conciliación antes de iniciar un proceso laboral.

Por último, en relación con las novedades de la Nueva Ley Procesal Laboral, puedo decir que son muchas, además de la oralidad: los jueces laborales peruanos pueden impartir justicia de acuerdo con la Constitución, los acuerdos internacionales sobre derechos humanos y los precedentes vinculantes del Tribunal Constitucional y la Corte Suprema. Se regulan procesos judiciales como el ordinario, el abreviado, el impugnativo de laudos arbitrales económicos, el cautelar y los no contenciosos. Las actuaciones realizadas en audiencias son grabadas en audio y video, salvo las de conciliación, y estas grabaciones serán incluidas en el expediente. Se implementa la notificación electrónica. Los prestadores de servicios pueden comparecer en el proceso laboral sin necesidad de abogado cuando el total reclamado no supere las 10 URP, y será facultad del juez solicitarlo si se supera dicho límite, hasta las 70 URP. Si el demandado no niega expresamente los hechos señalados en la demanda, estos se considerarán admitidos. También está la presunción de laboralidad. Las organizaciones sindicales pueden comparecer en el proceso, en representación de sus miembros, sin necesidad de contar con poder especial para ello. Igualmente, es improcedente la reconvención. Para el acuerdo conciliatorio o para la transacción que ponga final al proceso laboral, se deberá superar un test de disponibilidad de derechos. La conciliación administrativa laboral será obligatoria para el empleador y facultativa para el trabajador. Finalmente, en los distritos 
donde ya se encuentra implementada la Nueva Ley Procesal Laboral, los jueces cuentan con un sistema de planilla electrónica.

En cuanto a las recomendaciones, debo decir que para que funcione este cambio en el proceso laboral es necesario un cambio de actitud en todos: en las partes, en los abogados y en los jueces; asimismo, debe haber una capacitación adecuada, y todo ello debe ir acorde con determinados principios que ayuden a que la oralidad y los demás principios hagan exitosa la aplicación de la nueva ley. Considero, por último, que no deberíamos caer en la supletoriedad del Código Procesal Civil: no debemos permitir que su aplicación supletoria revierta los efectos de la oralidad buscados con la Nueva Ley Procesal Laboral.

Muchas gracias.

\section{Germán Ramírez-Gastón}

Muchas gracias por su participación y comentarios, doctora Cynthia Briceño.

Como hemos podido observar, hay muchos puntos por debatir. No quiero abusar del tiempo de nuestros distinguidos panelistas, ni de la audiencia; por lo tanto, sin más preámbulos, pasaremos a escuchar las preguntas que estimen pertinentes.

\section{Ronda de preguntas}

\section{Público}

Dirijo esta pregunta al doctor Eduardo Mercado. Quisiera saber si piensa que la falta de capacitación en los abogados y en algunos jueces, o la falta de adaptación al nuevo proceso, no genera una inseguridad jurídica dentro de todo el proceso, además de una indefensión de los trabajadores y empleadores con esta nueva ley laboral.

\section{Eduardo Mercado Villarán}

La pregunta contiene dos temas de análisis. El primero es el aspecto de la adaptación y la capacitación, no solo de la magistratura, sino, como bien se señala, de los abogados. 
Definitivamente, esta nueva ley trae - como lo mencioné- un cambio no solo de edición, sino de la forma de estudiar y practicar los procesos. Esto debería ir de la mano con las universidades, a fin de que los estudiantes puedan acercarse al nuevo proceso laboral. Asimismo, las partes del proceso (demandante, demandado y juez) deben hacer un esfuerzo por una mayor capacitación.

Una experiencia respecto al tema mencionado se da en la Universidad de Huancayo, que tiene una sala de audiencias creada exclusivamente para los estudiantes de derecho, donde estos practican desde hace casi seis meses o un año. Es una práctica que normalmente no se ha hecho, pero que me parece importante porque el nuevo esquema genera la posibilidad de inventar una serie de foros que podrían ayudar a la capacitación con respecto a la nueva ley.

En cuanto a los abogados, sí tienen una obligación particular: capacitarse. Recibiremos importante ayuda de los jueces, que son como "los directores de la orquesta", quienes van a poner coto a muchos hechos que sucedían y que ya no deben ocurrir con la nueva ley. Por ejemplo, al inicio de la implementación de esta norma, en la sede de Trujillo, se confundían dentro de una audiencia aspectos como "la confrontación de posiciones" - que consiste en presentar la teoría del caso y explicar cuáles han sido los hechos - con la parte de alegatos, debido a que hacían mención a los medios de prueba. Entonces, los jueces intentaban, de alguna forma, educar a los abogados y explicarles cuáles eran las partes materia de la audiencia y cómo deberían llevarse a cabo; incluso, cuando se iniciaba alguna de estas diligencias, los jueces indicaban una serie de reglas de juego que se tenían que valorar.

Con relación al aspecto de la indefensión, creo que no se estaría generando un problema al respecto. En algún momento se suscitó la duda porque existía la posibilidad de que un demandante pudiera actuar sin abogado ante una pretensión de menor cuantía; entonces, algunos abogados consideraron que se presentaba un supuesto de indefensión, dado que había excepciones que se podían plantear, defensas técnicas que ejecutar, etc., sin recordar la presencia del juez en el proceso, quien no va a tomar partido por ninguna de las partes, presencia que le da sentido a la actuación sin abogado referida en la norma. Además, si las audiencias se graban en audio y video, así como se pueden evaluar las conductas de las partes en pleno interrogatorio (si las respuestas son evasivas, si son certeras o no), también se puede analizar la conducta de 
los jueces. Por esta razón, pienso que la posición que tienen la partes del proceso (jueces, demandante y demandado) es una garantía contra la indefensión.

\section{Germán Ramírez-Gastón}

Evidentemente, la precisión que ha hecho el doctor Mercado acerca de la construcción que existe en el momento de presentar el caso, en la práctica la han visto con mucha dificultad muchos litigantes, quienes, por desconocimiento del nuevo proceso, mezclan la exposición de los hechos con la fundamentación jurídica que debe hacerse en la etapa de los alegatos y, por error, invocan una serie de dispositivos legales en la etapa de la exposición mencionada. Una cosa son los hechos concretos, prescindiendo de toda invocación legal, y otra la fundamentación jurídica con los alegatos. Muchas veces, los jueces tienen que corregir a las partes diciendo: "En esta etapa, cíñase estrictamente a los hechos, para después en la etapa de alegatos poder sustentar jurídicamente su posición con respecto a los hechos y pruebas que se han actuado".

Este conocimiento se puede lograr no solo en las aulas, sino también en conversatorios o en la práctica laboral efectiva y, por cierto, asistiendo a las audiencias, que ahora son públicas.

\section{Público}

Quedó pendiente explicar cómo funcionaría el asunto de la ejecución una vez que se declara el derecho en la sentencia.

\section{Carlos Quispe Montesinos}

La Nueva Ley Procesal del Trabajo se concibe bajo un esquema oral; pero, básicamente, la estructura oral se expresa hasta la denominada etapa decisoria, es decir, solo hasta la expedición de la sentencia. Uno de los problemas en la impartición de justicia es que los juicios tienen una larga duración y esto se da, justamente, por la ejecución de la decisión. Fíjense que quien más incumple y a su vez es más reacio en el cumplimiento de las sentencias es el Estado, a pesar de contar con un procedimiento especial para el pago de sus obligaciones judiciales, el que puede extenderse hasta cinco años. Nos encontramos, entonces, ante una realidad en la que las sentencias pueden ser expedidas pronto, 
pero no son cumplidas con la misma inmediatez, con lo que surge un problema de eficiencia en el sistema. Ello exige soluciones creativas en la dirección de los procesos.

Por ejemplo, recurrir a los juzgamientos anticipados. Me explico. En los procesos ordinarios hay dos audiencias: una primera, de conciliación, y solo si las partes no concilian se programa una segunda: de juzgamiento, que es donde se actúan las pruebas y se expide la sentencia. Me pregunto: ¿qué ocurre si, en un caso sencillo, al término de la etapa de conciliación, ante la falta de acuerdo de las partes el juez se atreve a sentenciar incluso antes de la audiencia de juzgamiento? Tengamos en cuenta que la Nueva Ley Procesal del Trabajo permite juzgar anticipadamente. Esto va a generar un mensaje para el siguiente proceso, en el que la misma demandada se encuentre en situación de incumplimiento; irá más predispuesta a conciliar, pues sabrá que, si no concilia, se expone a una sentencia inmediata contraria a sus intereses. Esto lo vamos a ver en distritos judiciales como Lima, en donde son demandadas -o tienen su domicilio - las empresas grandes y que tienen un número importante de procesos similares en los que son demandadas, por los mismos temas, por una pluralidad de trabajadores de manera individual. Si en un primer caso, uno segundo y uno tercero existe una línea uniforme de pronunciamientos judiciales, entonces la empresa va a saber que normalmente no va a ser vencedora en el juicio o que la sentencia no le va a ser tan favorable, más aún si sabe que el juez ejerce la facultad de juzgar anticipadamente. Ello debe llevar a que la empresa se encuentre presta a conciliar, y la conciliación va a implicar que sea puntual con las fechas de pago, con lo que evitará que el proceso tenga que discurrir en todas sus etapas, como la de ejecución, por ejemplo.

Entonces, el tema de la ejecución es un problema que no lo soluciona la oralidad, pero que sí requiere soluciones creativas, como las que estamos presentando, para evitar llegar a situaciones en las que se tengan que, forzadamente y contra la voluntad de quien ha sido vencido en el juicio, ejecutar las decisiones.

Un aspecto que también sirve es el de las facultades que tiene el juzgador para imponer sanciones. El importe de las multas por temeridad o mala fe se ha incrementado sustancialmente. Si existiera un sistema efectivo de cobro por multas, va a ser más conveniente que la empresa cumpla con la decisión expedida por el juzgado o, eventualmente, con el acuerdo arribado en la conciliación, que exponerse no solo a la ejecu- 
ción de su patrimonio para la satisfacción de la obligación que debe cumplir, sino también al pago de la multa pecuniaria. Entonces, hay mecanismos, pero el tema de la ejecución va a seguir siendo un problema en el esquema oral.

\section{Público}

El numeral 2 del artículo 2 de la Nueva Ley Procesal del Trabajo señala que, en el proceso abreviado laboral, puede tramitarse una demanda de reposición cuando esta se solicite como pretensión principal única. Por su parte, el Pleno Jurisdiccional Supremo Laboral de este año ha establecido que los reclamos derivados de despidos incausados y fraudulentos, en términos de la jurisprudencia del Tribunal Constitucional, pueden ser tramitados en el proceso laboral abreviado, pudiendo ordenarse la reposición del trabajador. ¿Cómo quedaría entonces el proceso de amparo en esta materia, considerando lo señalado por el precedente vinculante contenido en la sentencia emitida en el caso Baylón Flores, donde se establece que el Tribunal Constitucional es el competente para conocer de estos reclamos?

\section{Michael Vidal Salazar}

El artículo 2 de la nueva Ley Procesal del Trabajo establece que el proceso abreviado laboral - es decir, aquel que consta de una sola audiencia - es el proceso en el que se puede tramitar un pedido de reposición cuando esta figura como pretensión principal única. Hay una gran discusión para determinar a qué se refiere este inciso del artículo 2, y la hay porque los alcances van a tener una consecuencia importante. Una de ellas está relacionada, por ejemplo, con la discusión del futuro del proceso de amparo en materia laboral, considerando la interpretación del Pleno Jurisdiccional Supremo emitido hace algunos meses. En efecto, según este pleno, en el proceso abreviado laboral se podrían tramitar pedidos de reposición basados en las sentencias o en la jurisprudencia del Tribunal Constitucional, específicamente en la sentencia emitida en el caso Llanos Huasco contra Telefónica del Perú S. A., que establece la categorización de despidos que podrían llevar a la reposición del trabajador en vía de amparo, que comprenden el despido incausado, fraudulento y nulo. Yo, particularmente, cuando revisé este inciso, entendí que se trataba de un supuesto previsto para exigir la reposición cuando 
estaba basada en algunos supuestos del artículo 29 de la Ley de Productividad y Competitividad Laboral, referido a la nulidad de despido. Ello era tanto así, que el artículo hacía referencia a un pedido de reposición formulado como pretensión única, permitiendo que vaya acompañado de una pretensión accesoria, como podría ser el pago de las remuneraciones devengadas previsto por ley en los casos de despido nulo.

Ello, además, podría considerarse acorde con la posición de la jurisprudencia del Tribunal Constitucional, de la cual podría entenderse que a un juez ordinario no le está permitido ordenar la reposición en un supuesto distinto de los establecidos en el artículo 29 de la Ley de Productividad y Competitividad Laboral.

Lo antes señalado se ha sostenido a partir de lo indicado en la sentencia emitida en el caso Llanos Huasco, en la que se reafirmaría la validez de la regulación legal del despido y se justificaría la reposición en vía de amparo, debido a la naturaleza de dicho proceso, en el cual no puede otorgarse algo distinto que regresar el estado de las cosas a la situación anterior a la violación del derecho. Asimismo, se fundamenta en lo señalado en la sentencia emitida en el caso Baylón Flores, la que, en un esquema de amparo residual, considera que en los casos de despido incausado y fraudulento la vía ordinaria no resulta más satisfactoria, pues en esta vía el demandante no va a obtener su reposición.

Sin perjuicio de ello, el pleno va más allá debido a una preocupación relacionada con la indefensión en que se pueda encontrar el trabajador, por ejemplo, en el caso del despido fraudulento, que necesita ser acreditado con la actuación de medios probatorios distintos de los documentales, tomando en cuenta que el proceso de amparo no tiene etapa de actuación probatoria y que toda demanda en que dicha actuación se necesite es considerada improcedente.

El tema, pues, resulta bastante discutible. Sin embargo, si lo que se concluye es que la vía ordinaria laboral resulta más satisfactoria que la vía del amparo, habrá que cuestionarse si este último continúa siendo un proceso en el que se pueden tramitar reclamos derivados de despidos.

Ello es tan discutible, que el Tribunal Constitucional se ha refirmado en que va a conocer de despidos incausados y despidos fraudulentos, lo que ha originado que en este momento existan dos visiones sobre el tema: la de la Corte Suprema, a través de lo señalado por sus salas constitucionales y sociales, y la del Tribunal Constitucional. 


\section{Germán Ramírez-Gastón}

Muchas gracias, doctor Vidal. Evidentemente, siendo el proceso de amparo una medida de urgencia, se entiende que era razonable ir por esa vía y no, debido a la duración del proceso, por la vía ordinaria laboral. Pero, siendo la acción de amparo un complemento, una vía residual, y existiendo una vía igualmente satisfactoria, es probable que la amparización del derecho laboral tienda a desaparecer, como bien lo precisa el doctor Vidal.

Para terminar, dejo con el uso de la palabra a los panelistas, para que hagan algún comentario a manera de ronda final.

\section{Carlos Quispe Montesinos}

¿Qué pasó a raíz del Primer Pleno Supremo? Al inicio se pensó que los jueces constitucionales dejarían de ejercer competencia sobre los despidos incausados y fraudulentos y que estos serían resueltos por los jueces laborales. Sin embargo - y esto ha sido abordado en reuniones de coordinación entre magistrados de ambas especialidades-, el precedente Baylón Flores, contenido en la sentencia expedida en el expediente 206-2005-PA/TC, no ha sido dejado sin efecto: es precedente vinculante del Tribunal Constitucional, que mantiene su carácter vertical y horizontal para con los distintos órganos jurisdiccionales. Entonces, un juez constitucional no puede negarse a conocer un proceso de amparo en que se invoque un despido incausado o fraudulento, pues, conforme al citado precedente vinculante, tiene que hacerlo.

En concreto, lo que sucede o lo que va a suceder es que -como dijo Michael Vidal- los jueces constitucionales seguirán conociendo los procesos de amparo cuyo contenido sea una pretensión de despido incausado o fraudulento, aunque si una demanda de esta naturaleza es presentada ante un juez laboral, este también debe conocerla. Entonces, en cierta manera, estamos volviendo a una suerte de alternatividad en las vías procesales en lo concerniente a dichas materias, pues el justiciable que se presente como víctima de un despido fraudulento o incausado podrá optar si acude al juez constitucional mediante el amparo o al juez laboral vía un proceso abreviado. 


\section{Germán Ramírez-Gastón}

Evidentemente, lo que hace falta es un sinceramiento de las normas sustantivas. Desde el precedente Baylón Flores ya han transcurrido aproximadamente doce años $\mathrm{y}$, sin embargo, las normas no se han modificado y siempre el juez o las partes deben remitirse a las sentencias del Tribunal Constitucional. Creo que dicho sinceramiento resulta imperativo, pues recurrir constantemente a explicaciones, fundamentaciones y sentencias no contribuye a la claridad de las normas ni, menos, a la celeridad del proceso laboral, haciéndolo abigarrado y engorroso al tener que hacerse referencia a una serie de antecedentes que resultarían innecesarios si las normas fueran claras.

\section{Cynthia Briceño Jiménez}

La posición de una parte demandada, en un proceso ordinario, tiene mayor posibilidad de defenderse que en un proceso de amparo, en la medida en que no hay un método probatorio en una acción en la vía constitucional.

\section{Germán Ramírez-Gastón}

Creo que estos temas van a seguir dando mucho que hablar, pero antes de terminar quiero expresar mi agradecimiento a los distinguidos panelistas por sus brillantes comentarios y, en especial, a la revista Ius et Praxis por habernos convocado a esta interesante jornada de capacitación, intercambio de ideas, debate y reflexión sobre los alcances de la Nueva Ley Procesal del Trabajo.

Muchas gracias a todos por su presencia. 